\title{
VICO E A ORDEM DE ESTUDOS DE SEU TEMPO: A LIGAÇÃO ENTRE CONHECIMENTO E ÉTICA
}

\author{
Vladimir Chaves dos SAntos*
}

\begin{abstract}
RE SU M 0: Vico criticou a racionalidade que predominava em seu tempo e propôs outra como alternativa. No início dessa empreitada, sugeriu o engenho como perfil de inteligência que um programa pedagógico deveria fomentar. $\mathrm{O}$ engenho pensado por Vico deveria ser apto a restabelecer a ligação entre conhecimento e ética, algo que, segundo esse filósofo, teria sido abandonado pelas filosofias da moda na virada do século XVII para o XVIII. Além disso, o engenho poderia revigorar a inventio, uma das principais faculdades da retórica clássica, então menosprezada pela filosofia moderna. 0 ponto de partida do impulso inovador da filosofia de Vico foi a contestação de alguns princípios e conseqüências da filosofia de D escartes, urna grande moda filosófica à época do napolitano.
\end{abstract}

Palavras-chave: Educação. Retórica. Engenho.

\section{VICO AND THE PLAN OF STUDIESIN HISTIME: THE CONNECTION BETMEEN KNOMLEDGE AND ETHICS}

A BSTRA CT: Vico criticized the prevalent rationality in his time and proposed another one as alternative. In this enterprise, Vico suggested the wit as the profile of intelligence that every pedagogical plan should foment. The wit thought by Vico should be able to restore the connection between knowledge and ethics. It's something that, according to this philosopher, would have been abandoned by the vogue's philosophies on the turn of the seventhieth to the eighthieth century. Moreover, the wit cold revigorate the inventio, one of main classical rhetoric faculties, often disqualified by the modem philosophy. The starting point to Vico's innovator impulse was the contestation of some principles and consequences of D escartes' philosophy, a great philosophical vogue on time of the Napolitan.

Key words: Education. Rhetoric. Wit.

* Bacharel, mestre e doutorando em Filosofia pela UNICAMP. E-mail: vlasanto@ terra.com.br

E duc. Soc., Campinas, vol. 24, n. 85, p. 1277-1294, dezembro 2003 
$\mathscr{P}$ ouco se tem estudado os primeiros momentos da filosofia de Giovarini Batista Vico (1668-1744), quando então se preocupava com pedagogia e filosofia da ciência. 0 desenvolvimento dessas suas preocupações iniciais o levou à elaboração de uma teoria do conhecimento, a partir da qual poderia, mais tarde, em sua grande obra, Principi di Scienza N uova, lançar-se à tarefa de formular os princípios do método histórico e sistematizar as humanidades em geral. A Scienza N uova de Vico pretendeu significar, tal como ele a vislumbrou, um novo campo de reflexões e pesquisas, uma novidade para as preocupações de sua época. Sabe-se que a nova teoria do conhecimento de Vico nasceu de sua polêmica contra o cartesianismo, então, na virada do século XVII para o XVIII, uma grande moda filosófica; ele era contra tal epistemologia matematizante, rígida demais por rejeitar outras formas de conhecimento que escapam à quantificação (Assmann, 1985, p. 56) ou que por natureza convivem com 0 "dubitável".

Muito menos ainda se discute o fato de que os primeiros momentos dessa polêmica na obra de Vico ocorreram no âmbito da pedagogia. Ao avaliar a ordem de estudos dos modernos, que seria baseada na crítica, ou arte de julgar, e contrastando-a com a ordem de estudos dos antigos, que seria baseada na tópica, ou arte de inventar os argumentos, ${ }^{1}$ Vico fez um diagnóstico das conseqüências nocivas que a epistemologia cartesiana poderia causar à pedagogia, partindo do princípio de que o conhecimento não deve ser apenas verdadeiro, mas tem que ter um valor ético-social, isto é, uma relação com o bem comum da sociedade. De sua insatisfação com um modelo "cartesiano" de pedagogia, irrompem os primeiros lampejos de uma crítica que se estenderia até o terreno propriamente epistemológico de uma apreciação da metodologia científica, que culminaria na elaboração de uma nova teoria do conhecimento e de um novo método de pesquisa.

Em 1699, Vico assumiu o cargo de professor de retórica da Universidade de Nápoles. Uma de suas funções era abrir o ano letivo com uma preleção inaugural. Entre 1699 e 1708, Vico fez sete preleções que dissertavam ou sobre os fins dos estudos, como nas primeiras seis, ou sobre o método de estudar, como na segunda parte da sexta e na sétima inteira (Vico, 1953, p. 33). As três primeiras tratam principalmente dos fins dos estudos que convêm à natureza humana, as duas outras principalmente dos fins políticos, a sexta do fim 
cristão. Nessas preleções, ficava clara a preocupação de Vico com relação aos fins éticos do conhecimento.

Porém, é na sétima preleção, A ordem de estudos do nosso tempo (Vico, 1977), que Vico tornou pública pela primeira vez sua oposição anticartesiana ao retomar aquela questão renascentista da querela dos antigos e dos modernos: qual a melhor maneira de estudar, a dos antigos ou a dos modernos? A crítica serviria como instrumento comum para julgar a verdade em todas as ciências e artes; ela nos daria aquela verdade primeira da qual se está certo até no ato de duvidar a certeza do cogito (D escartes, 1993, p. 15) -, pela qual se acreditou que tivesse sido quase liquidada a Nova Academia de Carnéades - então escola dos céticos gregos (Vico, 1977, p. 793). A crítica seria a arte do discurso verdadeiro.

O que Vico chamou de crítica era antes de tudo um instrumento (idem, ibid., p. 797)² que nas mãos dos modernos serviu para subordinar todos os outros instrumentos de pesquisa ao seu crivo. À crítica estão associados o método geométrico, que pretende dominar o terreno dos raciocínios, e a análise, que pretende dominar o terreno das concepções de idéias, ambos subordinados ao interesse da crítica, que é 0 juízo em vista da verdade. 0 método geométrico é 0 raciocínio cuja principal característica é a sua integridade total, porquanto nele não se pode negar nenhuma parte do processo dedutivo sem se abalar os fundamentos (idem, ibid., p. 801). A análise pretende servir à concepção de idéias partindo do princípio de que tudo é passível de simplificação, e propõe-se a conceber idéias claras a partir da explicitação de idéias confusas, de tal maneira que ela não acrescenta nada de novo (idem, ibid., p. 807), mas apenas esclarece aquilo que já foi dado.

A epistemologia cartesiana englobava, portanto, a análise, o método geométrico e a moderna crítica, e ganhou a denominação de método cartesiano, cuja aplicação no ensino poderia ser chamada de método moderno de estudos, segundo os termos de Vico. Nessa preleção inaugural versada sobre a ratio studiorum (ordem dos estudos), Vico apontou uma série de desvantagens que a nova crítica poderia acarretar aos estudos.

Em primeiro lugar, a Vico desagradava o fato de os modernos afastarem-se da tópica (idem, ibid., p. 797). Aos modernos interessaria unicamente a verdade; as coisas verossímeis que circundam a ver- 
dade deveriam ser vistas como falsas, sem tópica alguma. Vico então se lançou a uma defesa do verossímil, alegando que na maioria das vezes este é verdadeiro e raramente falso. 0 filósofo de Nápoles colocava-se contra aquele tipo de dúvida hiperbólica (D escartes, 1994, p. 13), e para ele não bastou só o verdadeiro. Proferiu então uma pergunta dirigida tacitamente aos cartesianos e à crítica moderna ou a todos aqueles que sustentam verdades absolutas: "Mas como podem estar certos de haver visto tudo?" (Vico, 1977, p. 798). ${ }^{3}$ Neste sentido, haveria muito a se aprender com a tópica da oratória, que não se diz plena enquanto houver algo sem tratamento, algo que possa ser usado como termo médio e que aos ouvintes fique a desejar (idem, ibid., p. 794).

Em segundo lugar, a crítica ensinada aos jovens faria violência à natureza, pois para purgar a verdade primeira de todo falso e de toda suspeita de falsidade, os críticos colocaram-na antecedentemente, fora e sobre todas as imagens sensíveis (idem, ibid., p. 797). O ra, os jovens não excelem em outra faculdade da mente senão na fantasia e na memória; a razão é mais potente na velhice. Vico considerou que a crítica era ensinada aos jovens por demais prematuramente. A crítica não deveria servir de impedimento a que se cultivasse a fantasia e a memória bem como as artes que se valem destas, tal a pintura, a poesia, a oratória e a jurisprudência. É evidente para Vico que a inteligência não é estanque e tem formas distintas conforme a índole da idade. Nesse ponto, elogiou os antigos, para os quais a geometria era a lógica dos jovens; os antigos ensinavam aos jovens essa ciência que não pode ser bem aprendida sem a capacidade de configurar-se imagens. Com relação à ordem dos estudos, dever-se-ia imitar os médicos antigos, que se voltavam àquilo a que a natureza tende (idem, ibid.). ${ }^{4}$

Assim, Vico enunciou um princípio pedagógico que veio contra um tipo de orientação cartesiana: "como a invenção dos argumentos precede, por natureza, o juízo sobre a sua verdade, assim a tópica deve ser a doutrina preliminar" (idem, ibid.). Portanto, a tópica, como matéria de ensinamento, deve preceder a crítica. Sob o mesmo ponto de vista, ele considerou que a lógica formal deveria ser ensinada por último, pois, sem uma bagagem empírica de imagens e opiniões, a lógica ou é útil por incompreensível, ou é compreensível, porém inútil (idem, ibid., p. 801). Não violentar a natureza da mente dos jovens, que é altamente ligada ao sensível e ao concreto, e deixar 
que eles se habituem gradualmente à razão segundo a índole de sua idade, esta é uma das diretrizes da pedagogia de Vico.

Mas, ao que parece, a maior desvantagem do ensino baseado na nova crítica era a sua deficiência ética (idem, ibid., p. 809). ${ }^{5}$ Vico esperava que os adolescentes fossem educados, sobretudo no senso comum, a fim de que na vida prática da maturidade não prorrompessem em atitudes estranhas e arrogantes; contudo ele temia que isso fosse sufocado pelo método crítico dos modernos, que afastava da mente tudo que é verossímil (idem, ibid., p. 797). Segundo Vico, assim como a ciência nasce da verdade e 0 erro da falsidade, o senso comum nasce da verossimilhança (idem, ibid.). Tomadas de posição estranhas e arrogantes seriam derivadas de uma falta de prudência e eloqüência, e isso ocorreria porque, ao se rechaçar o senso comum, não restaria uma regra para a prudência, tampouco se tornaria necessário adequar o discurso às opiniões dos ouvintes.

Esse prejuízo se daria, sobretudo, porque o fim único dos estudos posto pela crítica era a verdade, e mais precisamente um conceito matemático de verdade, cuja principal propriedade é a necessidade lógica. Aos olhos de Vico, se a educação se guiasse apenas em vista da verdade, isso produziria danos à doutrina moral e civil e à eloqüência (idem, ibid., p. 809-811). De fato, daí decorre uma desvantagem para todas as humanidades. Ele advertiu que ao passo que a "república das letras" se dedicava com máximo zelo às ciências naturais, deixava abandonados os ensinamentos concernentes a todas as matérias relativas à república mesma; posto que 0 fim último dos estudos era a verdade, investigava-se a natureza das coisas porque parece exata, mas não a natureza dos homens porque é incertíssima em virtude do arbítrio. Desse modo, o ensino centralizado nas ciências naturais faz com que os jovens não se conduzam na vida civil com suficiente prudência nem saibam colorir o discurso com apelo aos costumes e inflamá-lo com as emoções. Ademais, aqueles que se preocupam tãosomente com 0 verdadeiro dificilmente encontram os meios e mais dificilmente atingem os fins da vida civil (idem, ibid., p. 811). Uma vez que os afazeres da vida prática são avaliados com base em situações e conseqüências, freqüentemente adversas e contrárias ao fim civil, "os fatos humanos não podem ser avaliados segundo a reta regra da mente - a verdade primeira -, que é rígida, mas segundo aquela medida flexível usada em Lesbos, que não quer adaptar os corpos a si, mas se dobra sobre os corpos" (idem, ibid.). 
A defesa do humanismo nessa dissertação, que é o motivo dominante das anteriores preleções inaugurais, moveu-se a partir da exigência de reconhecer a variedade dos fatos humanos e das condições que a determinam, variedade que a experiência revela em toda sua riqueza, mas que não se deixa reconduzir a explicações simplificadas e a critérios rígidos de avaliação (Vico, 1952, p. 12). A esse propósito. Vico disse que

a ciência diferencia-se da prudência nisto: na ciência excelem aqueles que aduzem urna única causa da qual são produzidos múltiplos efeitos naturais; na prudência, ao contrário prevalecem aqueles que investigam as quantas causas múltiplas de um único fato, para conjeturar qual seja a verdadeira. (Vico, 1977, p. 811) ${ }^{6}$

Ele buscou, mais amplamente, granjear méritos e espaço às ciências conjeturais, a partir do caso específico da prudência, valorizando-as tanto quanto as ciências exatas, especialmente porque abrangiam a política e o direito, inspirado pela medida de precaução de não reduzir a esquemas rígidos e deformados a riqueza da experiência humana.

É interessante notar que ao humanismo de Vico se deve sempre conceder a ressalva de que o homem não possui e não pode aspirar a possuir um conhecimento tão infalível e totalizante (idem, ibid., p. 791). A doutrina cartesiana pretendia estabelecer um único método (D escartes, 1965, II) e um único princípio - o cogito (idem, 1993, p. 15) - para todo o saber, e a partir daí deduzir todos os conhecimentos possíveis. Em oposição direta a isso que viria a ser chamado de racionalismo, Vico referiu-se continuamente às limitadas possibilidades cognoscitivas de que o homem dispõe e que não transcendem jamais os limites da experiência. Pois a mente humana, que é finita e não contém tampouco fez as coisas naturais, somente pode cogitá-las, mas nunca entendê-las, porque apenas pode mover-se entre os elementos externos das coisas (Vico, 1977, p. 62).

Portanto, não fazem bem aqueles que transferem ao exercício da prudência 0 critério de juízo de que se vale a ciência: esses avaliam as coisas conforme a reta razão, supondo que para conhecer 0 mundo não haja necessidade do apoio da experiência, uma vez que consideram poder extrair unicamente da razão os fundamentos de todo conhecimento. Os modelos racionalistas aplicados ao campo da política e do direito prendiam-se ao que deveria ser. Por excluí- 
rem o senso comum e o verossímil, ${ }^{7}$ contentando-se com uma única verdade, não a confrontavam com a opinião comum dos homens, a título de legitimá-la diante da comunidade à qual se refere. No entanto o senso comum, para Vico, não parecia tão mais incerto que as filosofias, pois que os equívocos decorrentes dos gêneros, isto é, da homonímia, teriam induzido os filósofos a erros mais que os sentidos induziram o vulgo a falsas opiniões ou a preconceitos (idem, ibid., p. 79-81).

O filósofo napolitano defendeu o senso comum como fonte do direito, uma vez que as leis das nações, no seu parecer, nasceram e devem nascer do interior de sua própria cultura, tendo sempre diante dos olhos a utilidade comum de uma nação específica, de que o senso comum é uma expressão bem sedimentada. Ilustra bem esse ponto a posição de Vico contra a idéia de que a Lei das XII Tábuas dos romanos tivesse sido importada dos gregos como uma versão das Leis de Sólon (idem, 1992, p. 513-519). Segundo Peter Burke, Vico era contra o difusionismo das idéias e dos costumes, vale dizer, contra a teoria de que as mesmas idéias e os mesmos costumes se difundem por povos diferentes a partir de uma mesma fonte (Burke, 1997, p. 70); ele defendia a teoria de que as idéias e os costumes ocorrem em correspondência com as necessidades específicas e os momentos históricos próprios de uma comunidade humana; a semelhança entre idéias e costumes de povos diferentes aparece então como um sinal de que o desenvolvimento histórico de qualquer comunidade em qualquer lugar segue algum tipo de padrão ou ordem relativa.

A defesa que Vico fez do senso comum teve seu primeiro passo quando ele pretendeu extrair uma metafísica a partir dos significados que os escritores latinos davam a certos termos (Vico, 1977, p. 56); isso revelava uma convicção de que a raiz e o fundamento da filosofia devem legitimar-se perante uma comunidade humana, de que a linguagem é expressão, de modo que a filologia e a consideração de tal comunidade passem a ser ponto de partida obrigatório da indagação filosófica. O utrossim, a consideração da cultura de uma comunidade parece ser ainda mais importante quando se adentra na área pedagógica, no ensino e no aprendizado. Portanto, uma educação que não prepara os jovens para esse confronto com a comunidade tem sérias deficiências éticas. Com base nisso, o fim último dos estudos deveria conduzir também à prudência civil e não 
mais apenas à verdade, ou seja, os estudos não deveriam ter somente um compromisso epistemológico, mas também e acima de tudo um compromisso ético.

A união entre veritas e virtus dar-se-ia de maneira especial na poesia, uma vez que o poeta ensina com deleite aquilo que o filósofo ensina austeramente: os costumes, os deveres, a virtude, os vícios (idem, ibid., p. 819). Considerando-se o entusiasmo do cartesianismo pela difusão da matemática e da geometria em todos os âmbitos, teóricos ou práticos, torna-se evidente que a defesa da poesia assumida por Vico o colocava em posição diametralmente oposta. ${ }^{8}$ De fato, a crítica moderna seria contrária à poesia exatamente na medida em que, se ensinada prematuramente aos jovens, obnubila nestes a fantasia e eclipsa-lhes a memória (idem, ibid., p. 817).

A essa altura já se pode perceber que o que está em jogo neste estudo é a noção de inteligência, e a partir daí se questiona que tipo de inteligência deve uma pedagogia inspirar nos jovens. Vico criticou a noção estanque segundo a qual a inteligência seria apenas a capacidade de refletir abstratamente de acordo com o padrão da lógica tradicional, como se a inteligência não percorresse um processo de desenvolvimento correspondente a cada fase do desenvolvimento fisiológico do ser humano; ou seja, para ele não havia apenas um mesmo tipo de inteligência pelo qual podemos avaliar crianças, jovens e adultos. Fundamentalmente, Vico contestou a dissociação de inteligência e imaginação. Esta foi estimada como o primeiro momento daquela, sendo própria dos mais jovens e devendo ser fortemente estimulada nestes. Ademais, sem a imaginação - que é a capacidade de criar imagens, a qual, portanto, está ligada ao concreto - aquela capacidade lógica e ordenadora da razão não teria material cognitivo para organizar, de tal modo que a razão sem a imaginação perderia toda sua capacidade inventiva, correndo o risco de estagnar-se sob o registro da imitação, na medida em que não seria capaz de criar conhecimentos, mas apenas poderia aplicar conhecimentos já legados pela tradição.

A aproximação entre razão e imaginação parece ser uma faceta essencial do objeto deste estudo, que é o engenho. Um outro aspecto que também poderia esclarecê-lo aparece quando se considera que Vico distinguiu dois tipos de inteligência: a sutil e a aguda (idem, ibid., p. 814). Vale lembrar que nas elucubrações estéticas barrocas 
era comum ligar o engenho às agudezas da linguagem, como no caso de Gracián e Tesauro (Gracián, 1987; Tesauro, 1968). Para Vico, a inteligência sutil seria aquela que procede sempre por dedução, estabelecendo conexões entre coisas próximas. Já a inteligência aguda procede sempre por indução, discernindo semelhanças em coisas muito distantes e diversas. Para caracterizá-las, Vico lançou mão de imagens: a sutileza desenvolveria gradualmente seus raciocínios conectando uma idéia com a outra mais vizinha, de maneira geométrica, desenrolando-se como se fosse uma linha (Vico, 1977, p. 803). ${ }^{9}$ A agudeza seria formada pela interseção de duas linhas diversas, configurando um vértice. A sutileza primaria pela coerência lógica e a agudeza pela eloqüência de seus discursos (idem, ibid., p. 815).

Entre os ditos agudos, ocupa o primeiro posto a metáfora. Cabe ressaltar a importância da metáfora para Vico: o elogio a esse tropo foi enunciado por ocasião de uma crítica ao método geométrico transferido à física e, mais precisamente, à forma condensada que os físicos conferiam às suas dissertações, à semelhança de demonstrações geométricas, o que obstruía a possibilidade da eloqüência; de fato, ele defendia os direitos da metáfora mesmo nas dissertações da física (idem, ibid., p. 803). Inicialmente a metáfora se apresentou na obra de Vico como um brasão da inteligência aguda. Já na Scienza N uova, a metáfora veio a lhe servir como chave para entender a sabedoria poética dos homens heróicos e sob que registros operavam suas mentes (idem, 1992, p. 193, § 404).

A caracterização desses dois tipos de inteligência tem aspectos culturais e históricos. Quanto a seus aspectos culturais, Vico seguiu o princípio de que "os engenhos são formados pelas línguas, e não as línguas pelos engenhos" (idem, 1977, p. 815). ${ }^{10}$ A ssim, a língua francesa, que, segundo Vico, abundava de nomes de substâncias abstratas, naturalmente assumia a máxima generalidade das coisas, e, por isso, era mais adequada ao gênero didático de falar, que é condensado e severo. Vico afirmou que ao passo que os italianos louvam seus oradores porque falam de modo copioso, claro, eloqüente, os franceses louvam os seus porque pensam coisas verdadeiras,

e quando querem dar um nome à virtude da mente de unir velozmente, convenientemente e felizmente coisas díspares, que por nós é dita "engenho", esses a chamam "espírito" e assim designam a força da mente, que consiste na composição, com a coisa mais simples, porque as 
suas mentes sutilíssimas excelem, não na composição, mas na simplicidade dos pensamentos. (Idem, ibid.) ${ }^{11}$

Desse modo, a nova crítica e a análise (que é o assunto da matemática), enquanto são despojadas de toda relação com o concreto, são ditas "espirituais", "simples" ou "verdadeiras" e, segundo Vico, puderam ser inventadas em toda a orbe terrestre somente pelos franceses, em virtude de sua sutilíssima língua, que seria adequada à formação de proposições simples, ordenadamente deduzidas, cujo único fim fosse a verdade. Além da parcialidade explícita dessa apreciação acerca da língua francesa, no entanto há de se levar em conta que Vico estava retratando implicitamente a linguagem de cartesianos e lógicos de Port Royal, associando ao caráter metódico e ao rigor lógico a idéia de sutileza.

Q uanto a seus aspectos históricos, Vico considerou que a inteligência sutil era tipicamente moderna e o gênero de discutir árido e dedutivo dos críticos teria se consagrado recentemente, retomando uma tradição estóica (idem, ibid., p. 799; cf. idem, ibid., p. 123). Vico tomou de Cícero a idéia de que foram os estóicos os primeiros a dedicar-se exclusivamente à crítica, assim como os acadêmicos céticos teriam se dedicado exclusivamente à tópica, a qual seria propícia à eloqüência (idem, ibid., p. 799; cf. idem, ibid., p. 121). Ele sugeriu que quanto mais as antigas escolas se distanciaram da crítica tanto mais foram fecundas. Aos estóicos, como aos modernos, aprazia considerar que a mente é a regra do verdadeiro (idem, ibid., p. 799801), ${ }^{12}$ vale dizer, eles recusavam o auxílio dos sentidos, opondo-se nisso aos epicuristas; eles estimavam que o sábio não deveria ter opiniões - tinha de ter certezas - e por isso assumiam como ponto de partida coisas indubitavelmente verdadeiras por si mesmas e as concatenavam mediante as verdades segundas, como uma corrente, até as coisas dúbias, usando como arma o sorites, uma cadeia de silogismos na qual a conclusão do silogismo precedente é assumida como a premissa do silogismo subseqüente.

A semelhança com a maneira de raciocinar empregada por D escartes nas suas Meditationes não é mera coincidência. ${ }^{13}$ Vico afirmou que, dentre todos, os estóicos foram os mais crus e sucintos na argumentação. Fica clara a correlação entre a inteligência sutil, que raciocina linearmente, e a argumentação por sorites, cuja forma é de corrente. 
Por motivos éticos Vico preferia a inteligência aguda à sutil. Em suma, a inteligência sutil seria útil apenas à ciência, porque chega mais facilmente à verdade; em contrapartida, a inteligência aguda, por saber tirar proveito do verossímil, estaria mais apta para o confronto com a comunidade, por meio da eloqüência. Poderia conhecer mais facilmente todas as circunstâncias que envolvem o arbítrio humano, sejam suas paixões, os caráteres próprios da virtude e do vício, ou os elementos dos costumes, avaliando os fatos humanos não segundo uma regra tão rígida como a verdade cartesiana, que era entendida pelos estóicos como a coerência proposicional resultante de um sorites, mas segundo uma regra mais flexível - 0 verossímil -, que se pode adaptar aos fatos humanos para conjeturar a verdade. Uma tal inteligência seria capaz de constituir uma sabedoria ciente também de prudência civil, e essa é uma perspectiva ética que faltaria à inteligência sutil.

Esta é experta na crítica, e a inteligência aguda é experta na tópica. Mas isso não significa que a inteligência aguda esteja incapacitada para a pesquisa científica; tampouco Vico foi um inimigo da crítica. Essa sua sétima seção inaugural foi declaradamente inspirada no D e A ugumentis Scientiarum, de Francis Bacon (idem, ibid., p. 790), e neste sentido manifestava um interesse pelo progresso da ciência. Vico pretendia com sua dissertação advertir quanto às desvantagens e ressaltar as vantagens tanto do modo moderno de se fazer ciência como do antigo. Ele julgou que a tópica e a crítica tinham seus defeitos e, assim, procurou compensar uma com as vantagens da outra. 0 mal da tópica é que por meio dela algumas vezes se aceita o falso; a crítica, por seu turno, peca porque não acolhe também o verossímil. Um plano pedagógico completo deveria começar com a tópica, a fim de que os adolescentes fossem preparados, com o senso comum, para cultivar a prudência e a eloqüência, e, com a fantasia e a memória, as artes; por fim, deveriam aprender a crítica, para julgar com seu próprio juízo a totalidade das coisas em que foram instruídos, ponderando sempre uma tese com sua oposta, uma vez que já foram enriquecidos dos lugares da tópica (idem, ibid., p. 801).

O escopo do programa educacional de Vico consiste em que os jovens se tornem verdadeiros nas ciências, solertes na prudência, fecundos na eloqüência, ricos de fantasia na poesia e na pintura, e de memória na jurisprudência, de tal modo que possam prevenir-se contra a temeridade de se discutir sobre o que não se conhece completa- 
mente e contra a ortodoxia daqueles que consideram verdadeiro somente o que é ensinado por uma autoridade (idem, ibid.).

No caso da poesia, a crítica só lhe é prejudicial quando ensinada prematuramente; entretanto, se os jovens já se encontram vigorosos na fantasia e na memória, segundo Vico, a crítica pode ser favorável à poesia, pois o bom poeta não se deleita com o falso, mas com 0 verdadeiro, não, porém, com uma forma cotidiana de verdadeiro, e sim com uma espécie mais excelente e sublimada (idem, ibid., p. 819). Da mesma maneira, o método geométrico permite que se imprima coerência em uma fábula, de modo que os personagens que foram introduzidos no princípio permaneçam coerentes consigo próprios ao longo da estória; permite também evitar paralogismos e encontrar falácias (idem, ibid., p. 817).

Vico estava mesmo interessado no progresso das ciências; talvez, por isso, não fosse adepto da veneração absoluta aos antigos tampouco do culto irrestrito à ciência moderna. Ele não obedecia cegamente nenhum dos lados. Louvava as conquistas da nova crítica e do método geométrico, especialmente na matemática. Contudo, apesar da pretensão da nova crítica de ser comum a todas as ciências e artes, Vico rejeitava a sua aplicabilidade à sabedoria prática, à política e ao direito. Nesse campo, Vico concluía que a doutrina dos antigos permanecia superior e por isso criticava os cartesianos por distraírem a atenção ao mundo do homem. Vico fez um balanço das conquistas intelectuais feitas até então e traçou um plano para reorientar as pesquisas científicas, avaliando os limites e as possibilidades próprios de cada ciência, e indicando os instrumentos mais adequados a cada uma. Ele aspirava com isso a conduzir os esforços científicos para novas empresas, tanto nas humanidades quanto nas ciências naturais.

Nesse ponto, é importante notar que Vico entendia a ampliação e o progresso do conhecimento justamente na perspectiva da confecção do novo. O novo e a inventio parecem, inclusive, uma preocupação constante dos barrocos. Neste sentido, Vico condenava o comodismo que, aos seus olhos, instaurara-se nas ciências de sua época. ${ }^{14}$

$\mathrm{Na}$ medicina, ele criticava aqueles que procediam com base em teorias gerais e se esforçavam mais em não corromper os sistemas que em curar o doente; da mesma maneira que Bacon notara que os galênicos se haviam enganado ao conjeturar com silogismos as causas das doenças, Vico repreendia os modernos por terem a intenção de fa- 
zer o mesmo usando do sorites (idem, ibid., p. 809). O ra, quem se vale do silogismo não produz nada de novo, porque a conclusão já está implícita na premissa; do mesmo modo, quem se funda sobre o sorites não faz outra coisa senão tornar explícita a verdade segunda que se escondia implicitamente na primeira (idem, ibid.). Entretanto, Vico advertiu que as doenças são sempre novas e diversas, como novos e diversos são os doentes. D a mesma maneira, na mecânica, duvidava da facilidade que a análise lhe proporcionava: a facilidade é perigosa porque debilita os engenhos, ao passo que a dificuldade os aguça. Vico mencionou o fato de as grandes invenções da modernidade, o canhão, as caravelas, o relógio, as cúpulas dos templos, terem sido concebidas antes que se divulgasse a análise (idem, ibid., p. 805). Q uanto à jurisprudência, não considerou imbuído desta quem apenas se valia do direito tético, isto é, do sumo e geral das regras, mas sim quem via nas causas as últimas e particulares circunstâncias dos fatos que merecem a eqüidade (idem, ibid., p. 77), vale dizer, quem via as exceções que permitem subtrair-se à lei universal. Na oratória, são bons aqueles que não vagam por lugares-comuns, mas aderem às circunstâncias (idem, ibid., p. 79). O s historiadores úteis não são aqueles que narram grosseiramente os fatos e as causas genéricas, mas aqueles que perseguem as circunstâncias últimas dos fatos e revelam as causas peculiares (idem, ibid.). $\mathrm{Nas}$ artes, excelem aqueles que adornam 0 arquétipo comum deduzido da natureza com circunstâncias não comuns, mas novas e admiráveis (idem, ibid.). D e maneira geral, Vico defendia a observação e 0 engenho como os procedimentos mais profícuos para as ciências e as artes.

Por essas mesmas razões, ele criticava os físicos de sua época que, entusiasmados pelo método geométrico, cessavam de contemplar a natureza e explicavam com esse método todo novo fenômeno como corolário da teoria física. Segundo Vico, para esses físicos, a teoria era a própria natureza e onde quer que alguém contemplasse 0 universo, este veria a mesma física (idem, ibid., p. 801-803). ${ }^{15}$ Conforme a imagem de que Vico se valeu, esses físicos se assemelhavam àquelas pessoas que herdaram casas nas quais nada se pode mudar, a não ser a mobília ou orná-las de acordo com a moda do tempo (idem, ibid.).

Nessa medida, o que mais importa na ciência não é a busca de uma verdade absoluta, mas a construção de hipóteses que permitam avançar cada vez mais sobre objetos ou problemas que preocupem 0 homem. De fato, Vico desejava o avanço da ciência experimental (idem, ibid., p. 131). Sob essa ótica, a ciência poderia liberar toda 
sua capacidade inventiva para resolver problemas específicos. A origem das ciências e a norma para reconhecer aquilo que é verdadeiro não deveriam ser procuradas em outra parte senão no "fazer" humano. As regras que observam a pesquisa científica devem ser traçadas, em última instância, pela própria capacidade inventiva da mente humana (Badaloni, 1988, p. 22). Em sua obra, A antiquíssima sabedoria dos itálicos, Vico anunciou um princípio que pretendia valer para todo conhecimento humano: o verdadeiro é o próprio feito, verum esse ipsun factum (Vico, 1977, p. 63).

Vico sustentou a noção de ciência como conhecimento da gênese ou conhecimento das causas (idem, ibid., p. 63, 81-83). Ele encontrava-se na esteira de uma tradição que passa por Galileu, Bacon, Hobbes, D escartes, Spinosa, entre outros. Para esses filósofos, o verdadeiro é aquilo que o homem, enquanto conhece, compõe e faz. Eles valiam-se dessa noção, sobretudo para compreender o mundo das matemáticas. Vico partiu do mesmo ponto e estendeu o princípio da identidade do verdadeiro e do feito também ao mundo ético-político. Não, porém, conforme a perspectiva de Hobbes (idem, 1952, p. 36), qual seja, que o homem, mediante um contrato racional, conscientemente se dá um Estado de direito; mas conforme a gênese e 0 desenvolvimento históricos desse mundo ético-político, pelo que 0 homem cria as suas condições de sociabilidade sem que tenha ou deva ter clara consciência disso (idem, 1992, §2).

Sob esse ponto de vista, Vico transformou o princípio de que verum esse ipsun factum (o verdadeiro é o próprio feito) em portão de entrada para as humanidades: 0 mundo das nações ou mundo civil, ao contrário do mundo natural, pode ser conhecido porque certamente foi feito pelos homens, e seus princípios podem ser encontrados dentro das modificações da própria mente humana (idem, 1992, p. 121, §331). D escartes, por outro lado, lançara mão da identidade do verdadeiro e do feito para sacramentar a verdade absoluta nas ciências e afirmar a auto-suficiência da razão, tomando como modelo a matemática: verdadeiro é só aquilo que é feito pela razão, e esta não necessita da experiência. ${ }^{16}$

Para Vico, o homem faz três operações para chegar ao saber: percebe, julga e raciocina (idem, 1977, p. 119). Com base nisso, talvez seja lícito dizer que a razão cartesiana tenha valorizado mais o julgamento e a ordenação das idéias, em detrimento da concepção 
delas. ${ }^{17} \mathrm{~A}$ título de revigorar a primordial mas esquecida função inventiva da inteligência humana, Vico sugeriu a cultura do engenho, que deveria encontrar novas idéias valendo-se de uma cuidadosa observação empírica para construir suas hipóteses.

Após esse panorama, torna-se possível perceber que a tônica da polêmica de Vico com o cartesianismo foi a crítica à deficiência ética dessa filosofia. Fundamentalmente, Vico criticou o cartesianismo por ter dado as costas ao mundo feito pelos homens. Do ponto de vista de Vico, isso se devia, em primeiro lugar, à obsessão pela verdade de tipo matemática; com efeito, a natureza, quantificada e matematizada, seria mais fácil de ser conhecida que o mundo humano, que não é suscetível de redução à quantificação. Neste sentido, a filosofia de D escartes aparecia como o correlato filosófico à condição de a sociedade moderna ter-se inclinado largamente para a instrução das ciências naturais matemáticas. As exigências da economia mercantil em expansão e a necessidade de domínio técnico da natureza conduziram à absolutização da matemática como único ramo do saber em que se podia confiar. Em segundo lugar, a "facilidade" das ciências naturais, em oposição à "dificuldade" das humanidades, teria embotado os esforços científicos, não tanto desejosos de novas teorias quanto comprometidos com o acúmulo de confirmações daquelas teorias já estabelecidas, 0 que refletia um certo comodismo nas ciências em geral.

O filósofo napolitano, por conseguinte, atacou o cartesianismo em duas frentes simultaneamente. Por um lado, ele propôs a revalorização do ensino de assuntos éticos que, segundo ele, haviam sido esquecidos pela pedagogia moderna. Além disso, defendeu a volta do ensino da tópica dos antigos, a fim de que se fomentasse nos jovens 0 engenho, ou inteligência aguda, que seria melhor facultado para constituir uma prudência civil. Por outro lado, no campo da pesquisa científica, Vico também defendeu o engenho como a faculdade certa para o conhecer, dotado de capacidade de observação e da perspectiva de encontrar o novo; isso porque ele percebia que a epistemologia cartesiana careceria de um princípio que cultivasse a inventividade. E, para resolver esses dois aspectos do mesmo problema, Vico sustentou a idéia de que o engenho é próprio para conhecer ou fazer (idem, 1977, p. 130), isto é, para a teoria e a práxis.

Recebido em fevereiro de 2003 e aprovado em julho de 2003. 


\section{Notas}

1. A tópica, oriunda da antiga tradição retórica, seria um método pelo qual se observaria todos os lugares-comuns acerca de uma questão proposta para se encontrar um argumento adequado e completo, em vista de se discutir com verossimilhança e eloqüência. Neste sentido, foi entendida por Vico como a arte de encontrar o argumento; a tópica seria o instrumento próprio para a inventio dos argumentos; cf. Vico, "De nostri temporis studiorum ratione", em 0 pere Filosofiche, Firenze: Sansoni, 1977, III, p. 798. Além disso, é preciso dizer que a defesa viquiana da tópica tem raízes na concepção aristotélica e ciceroniana; leia-se Aristóteles, Topiques, Paris: Belles Lettres, 1967; e Cícero, Topica, London: Loeb, 1976; cf. também Cícero, O rator, London: Loeb, 1988.

2. A título de comparação, veja-se a perspectiva diversa de Kant, segundo a qual a crítica não é um organon (instrumento), mas um cânon. Neste sentido, a crítica não teria um caráter construtivo, mas regulativo; cf. Kant, Crítica da razão pura, Cânon da razão pura, p. 633.

3. Cabe notar que um dos preceitos do método cartesiano era o de enumerar e rever exaustivamente os problemas para se ter certeza de não haver omitido nada, cf. D escartes, D iscours de la méthode, II.

4. Há que se ter em mente a diferença fundamental para Vico entre a geometria antiga e 0 moderno método geométrico. Aquela tinha uma relação umbilical com a imaginação e a exercitava sobremaneira. Já este se estabeleceu como um tipo de fórmula extraída do modo com que comumente os geômetras apresentavam suas demonstrações, que era à maneira de Euclides, e baseava-se na regra geral de que, dados alguns princípios (axiomas), as conseqüências (corolários) deveriam seguir-se automaticamente. O método geométrico requeria, portanto, o exercício do raciocínio lógico.

5. Não se deve deixar de mencionar o papel da moral e da medicina no pensamento de Descartes, cf. A s paix ões da alma. Entretanto, Vico considerou insuficiente o tratamento que D escartes dedicou à moral, alegando, entre outras coisas, que L ês passions de l'âme mais serve à medicina que à moral; cf. "Autobiografia", em 0 pere, p. 23. Também vale lembrar que o próprio método de Descartes foi fundado sobre uma moral declaradamente estóica, que no entanto apontava mais para uma reforma das opiniões do senso comum que para uma irrestrita rejeição delas, cf. D iscours de la méthode, III.

6. "Atque adeo hoc scientia a prudentia distat, quod scientia excellunt, qui unam caussam, per quam plurima naturae effecta perducunt; prudentia vero praestant, qui unius facti quam plurimas caussas vestigant, ut quae sit vera, coniiciant."

7. Descartes, por exemplo, tentou se conduzir sem o recurso aos doutos, à cultura, à moda, ao costume, ao exemplo, à pluralidade de opiniões, cf. D iscours de la méthode, II. Contra 0 verossímil leia-se D iscours de la méthode, I e VI.

8. Leia-se a crítica de D escartes à poesia, em D iscours de la méthode, I.

9. A propósito, veja-se a mesma imagem da linha empregada para esclarecer um procedimento do método de D escartes, cf. D iscours de la méthode, II. Veja-se também a crítica de Bacon à sutileza dos escolásticos, os quais teriam deixado de observar a natureza, apenas aplicando-se às suas próprias idéias, de modo que trabalhariam sobre si mesmos como a aranha sobre sua teia, produzindo teias de aranha de saber, admiráveis pela finura do fio e da obra, porém sem substância; cf. Bacon, The advancement of learning, Oxford: Oxford Univ., 2000, p. 24.

10. "[...] linguis ingenia, non linguas ingeniis formari [..]". Essa seria uma alusão à teoria do "gênio das línguas", formada na Itália e na França durante a Querela entre Antigos e Mo- 
dernos que irrompeu no início do século XVIII. De acordo com Nicolini, Vico nessa passagem conferia um papel puramente pedagógico às línguas; e nesse caso elas teriam uma natureza intelectualística. Já na Scienza N uova, a natureza das línguas seria não intelectualística, mas primitiva, rude, e por isso mesmo poética. A elucubração viquiana a seguir pautar-se-ia mais exatamente na querela também nacionalista entre 0 italiano Marquese Orsi e o francês D omenico Bouhours. Vico, assim como Orsi, defendeu as veneráveis glórias da Itália em oposição aos modernos franceses; em contrapartida, elogiou as virtudes espanholas das agudezas, em clara referência ao barroco espanhol de Gracián e Gongora, quando então Nápoles estava sob o jugo da Espanha. Leia-se Vico, 0 pere, notas das p. 198-200, e também Levine, "G.B. Vico and the Quarrel between the Ancients and the Moderns", em Journal of the H istory of Ideas, 1991, p. 68.

11. "Et cum hanc mentis virtutem distracta celeriter, apte et feliciter uniendi, quae nobis 'ingenium' dicitur, appellare volunt, 'spiritum' dicunt, et mentis vim, quae compositione existit, re simplicissima notant, quod subtilissimae eorum mentes non compositione, sed tenuitate cogitationum excellant."

12. A propósito, leia-se o elogio de Descartes à moral estóica, segundo a qual não há nada que esteja tão inteiramente em nosso poder como os nossos pensamentos; veja-se também a importância do juízo e do desprendimento com relação às antigas opiniões; cf. D iscours de la méthode, III.

13. Veja-se também a concepção de ciência como cadeia de razões dedutíveis em Descartes, D iscours de la méthode, II.

14. Veja-se também a crítica de Bacon ao abandono da arte da inventio e da descoberta nas ciências de sua época; cf. Bacon, The advancement of learning, Oxford: Oxford Univ., 2000, p. 107-108.

15. Cabe mencionar que Bacon já advertia para o erro de se adorar exclusivamente o entendimento humano, em detrimento da contemplação da natureza e das observações da experiência; cf. Bacon, The advancement of learning, Oxford: Oxford Univ., 2000, p. 30.

16. Para Descartes o conhecimento era tanto mais certo quanto mais distante da experiência, tal a aritmética e a geometria, cf. Regulae, II.

17. Neste sentido, a tópica seria um tipo de método de pesquisa, isto é, um instrumento, que não excluiria outros métodos, como a crítica e o método geométrico. 0 objetivo da crítica seria o juízo; 0 do método geométrico, a ordenação. Para Vico, o escopo da tópica seria a percepção do todo. D efender a tópica significou também acusar a filosofia moderna de valorizar apenas dois aspectos do saber: o julgar e o ordenar, menosprezando o perceber, que anda ao lado do descobrir e inventar.

\section{Referências bibliográficas}

ARISTÓ TELES. Topiques. Paris: Belles Lettres, 1967.

ASSMANN, S.J. Vico, um gênio solitário e renovador. Revista de Ciências H umanas, Florianópolis, v. 4, n. 7, 1985.

BACON, F. The advancement of learning. Oxford: Oxford Univ., 2000.

E duc. Soc., Campinas, vol. 24, n. 85, p. 1277-1294, dezembro 2003

Disponível em <http:/ / www.cedes.unicamp.br> 
BADALO NI, N. Introduzione a V ico. Firenze: Laterza, 1984.

BURKE, P. V ico. São Paulo: unesP, 1997.

CICERO. Topica. London: Loeb, 1976.

CICERO. O rator. London: Loeb, 1988.

DESCARTE S, R. D iscours de la méthode. Paris: Vrin, 1965.

DESCARTES, R. Les passion de l'âme. Paris: Vrin, 1986.

DESCARTES, R. Regulae ad directionem ingenii. Paris: Vrin, 1986.

DESCARTES, R. M editationes de prima philosophia: I, II, III. Campinas: IFCH/ UNICAMP, 1993-94. (Textos didáticos)

DESCARTES, R. Reglas para la direccion del espiritu. Madrid: Alianza, 1996.

GRACIÁN, B. A gudeza y arte de ingenio. Madrid: Castalia, 1987.

KANT, E. Crítica da razão pura. Lisboa: Fundação Calouste Gulbekian, 1994.

LEVINE, J.M. Giambattista Vico and the quarrel between the ancients and the moderns. Journal of the $\mathrm{H}$ istory of Ideas, Philadelphia, v. 52, n. 1, 1991.

TE SAURO, E. C annocchialle aristotelico. Berlin: Verlag, 1968. (Facsímile da edição de Torin, 1670).

VICO, G. La scienza nuova e altri scritti. Torino: Utet, 1952.

VICO, G. 0 pere. Milano: R. Ricciardi, 1953.

VICO, G. 0 pere filosofiche. Firenze: Sansoni, 1977.

VICO, G. Le orazioni inaugurali. Napoli: Centro di Studi Vichiani, 1982.

VICO, G. Princìi di Scienza N uova. Milano: Mondadori, 1992. 